\title{
$\underline{\text { Tunnels and Reserves in Monetary Policy Implementation }}$
}

\author{
William Whitesell*
}

May, 2003

\begin{abstract}
In recent years, some central banks have implemented monetary policy without reserve requirements by using a ceiling and floor for overnight interest rates established by central bank lending and deposit facilities. This paper analyzes a theoretical model of such a "tunnel" system and the benefits of adding reserve requirements to it. However, reserve requirements may involve social costs owing to the reserve avoidance activities of banks. The paper also presents a modified model with no reserve avoidance, where banks optimally choose to hold voluntary reserve requirements. The paper highlights the importance for central banks to consider such models in light of idiosyncratic features of their own institutional environment, which may importantly condition the advisability of any particular approach.
\end{abstract}

Keywords: monetary policy implementation, reserve requirements, overnight interest rates

JEL classifications: E4, E5

* Board of Governors of the Federal Reserve System (wwhitesell@frb.gov). I have appreciated comments from James Clouse, John Driscoll, Richard Porter, and Eric Swanson. The views expressed are those of the author and not necessarily those of the Board of Governors of the Federal Reserve System or others of its staff. 


\section{$\underline{\text { Tunnels and Reserves in Monetary Policy Implementation }}$}

\section{$\underline{\text { Introduction }}$}

Most major central banks conduct monetary policy using a short-term market interest rate as an instrument to achieve their ultimate objectives for the performance of the economy. Traditionally, central banks have tried to hit a target level of the short-term market rate by adjusting the aggregate supply of liquidity through open market operations or other means. In such circumstances, the central bank needs a predictable demand function for the liquidity it supplies. Reserve requirements have been one means of arranging for this, and they are still used for this purpose by some major central banks, including the Federal Reserve, the European Central Bank, and the Bank of Japan.

Reserve requirements create a known or predictable demand for balances held at a central bank on average over a maintenance period. Moreover, the period-averaging induces depository institutions to engage in intertemporal arbitrage of the reserve market interest rate, helping to keep it on target. However, central banks in Switzerland, Sweden, Canada, Australia, and New Zealand have found that they can conduct monetary policy satisfactorily without the aid of reserve requirements. The Bank of England retains a minimal level of reserve requirements, though merely to raise revenue for the central bank independently of the government budget and not for the purpose of implementing monetary policy. Clinton (1997), Guthrie and Wright (2000), and Woodford (2001) have described how a central bank can keep a policy rate on target, without reserve requirements, by relying on standing facilities: a lending facility at a penalty interest rate above the central bank's target rate and a deposit facility (or interest on excess balances held at the central bank) at an interest rate below the target rate. With the lending facility providing a ceiling for overnight rates and the deposit facility a floor, such a system has been called a channel, corridor, or tunnel. Canada, Australia, and New Zealand currently employ a tunnel regime with a 50 basis point band between lending and deposit rates.

This paper analyzes further the use of tunnel procedures and any role for periodaverage requirements in such a regime. The models of bank reserve management developed here draw from and contribute to a sizable literature, including work by Orr and Mellon (1961), Poole (1968), Campbell (1987), Kopecky and Tucker (1993), Clouse and Dow 
(1999), Furfine (2000), Guthrie and Wright (2000), Bindseil (2000), Woodford (2001), Bartolini/Bertola/Prati (2001 and 2002), and Heller and Lengwiler (2003). ${ }^{1}$ With a few exceptions, this literature has not addressed daily account overdrafts in the presence of multiday reserve requirements with uncertain future interest rates, and closed form solutions for such models have not previously appeared to the author's knowledge. ${ }^{2}$ This paper derives the full shape of the reserve demand curve, which is critically important for the implementation of monetary policy, as discussed further below. The paper also includes what is evidently the first formal model of voluntary reserve requirements.

The paper begins by analyzing a one-day tunnel model without reserve requirements, similar to one discussed briefly by Woodford (2001), and identifies the advantages of such a framework for estimating reserve demand, an essential activity in monetary policy implementation. Assuming Gaussian distributions for reserve supply and account balance uncertainties, the resulting distributions for market interest rates are then depicted. A key disadvantage of a pure tunnel regime related to the elasticity of demand is also identified.

A multi-day tunnel model is then developed and the effects of reserve requirements on the elasticity of demand are examined. While the tunnel framework may help the central bank hit its desired interest rate on settlement day, reserve requirements and expected future interest rates importantly shape the reserve demand curve earlier in a maintenance period. The paper points out the sensitivity of the key findings to detailed features of the relationship of private sector banks to the monetary authority. Seemingly minor modifications in institutional arrangements, such as whether overdrafts count toward reserve requirements, may change the structure of incentives profoundly and alter the behavior of the system.

The last section of the paper addresses a well-known trade-off associated with reserve requirements: While they may help reduce the variance of overnight interest rates, they may

\footnotetext{
${ }^{1}$ Models of the micro-mechanics of trading in federal funds have also contributed to this literature, including those of Ho and Saunders (1985) and Spindt and Hoffmeister (1988). ${ }^{2}$ Furfine (2000) set up such a problem and showed intertemporal Euler conditions without deriving demand curves. Longworth (1989) and Davies (1998) also allowed for overnight overdrafts with period-average requirements, but in different types of models. Longworth assumed perfect foresight about future interest rates and Davies allowed no interbank trading, while both used a uniform distribution for account shocks, rather than the general or Gaussian distribution functions used here. Clouse and Dow (2001) find numerical solutions for a multi-period model with overdrafts and period-average requirements assuming a constant, known market interest rate.
} 
also generate incentives for reserve avoidance activities that impair financial sector efficiency and that cannot be justified on optimal taxation grounds. The paper concludes with a stylized model that depicts circumstances in which the inefficiencies could be avoided through a system of voluntary reserve requirements.

\section{$\underline{\text { A One-Day Tunnel Model }}$}

In this section, we present a one-day tunnel model without reserve requirements and then provide motivation for examining a multi-day tunnel model with reserve requirements. In the one-day model, the central bank relies entirely on the ceiling and floor provided by its lending and deposit interest rates, respectively, to control the overnight market interest rate. ${ }^{3}$ To motivate the setup, consider a private sector bank with no previous involvement in overnight markets that decides to engage in direct clearing of transactions through the payment system operated by or in association with the central bank. The private bank opens an account at the central bank and begins using the account to clear transactions. ${ }^{4}$ The bank tries to track its account position with the central bank during the day, but is nevertheless subject to unexpected late payments or delayed accounting information, and therefore can determine its end-of-day position only within a margin of error given by a stochastic term, $\varepsilon$, where $\mathrm{E}(\varepsilon)=0$. During the day, the bank can trade central bank balances with other banks at the market rate, $i$, and does so to achieve a target account balance of $T$. If the bank's actual end-of-day account balance of $T+\varepsilon$ is positive, it earns interest at the central bank's deposit interest rate. Any end-of-day overdraft is booked as a loan from the central bank. The central bank has a target for the overnight rate of $i^{*}$, which it tries to hit with the help of a lending rate at $i^{*}+s$ and a deposit rate of $i^{*}-s$. The symmetry of these spreads around $i^{*}$ will be an important feature of the model. A graphic depiction of the representative bank's decision problem is provided in Exhibit 1. More formally, the key assumptions are:

\footnotetext{
3 A similar one-day tunnel model was discussed briefly by Woodford (2001). The analysis here is more thorough and the subsequent models, which include reserve requirements, are new contributions. Though not tunnel frameworks, the models of Furfine (2000) and Bartolini/Bertola/Prati (2002) are also similar in some respects to the one developed here. 4 At the Federal Reserve, such transactions include checks, automated clearinghouse payments, wire transfers, and transfers for cash of book-entry Treasury and agency securities. The paper uses the term "private bank" to represent any institution that may open a central bank account and participate in the payment system supported by the central bank.
} 


\section{Cost}

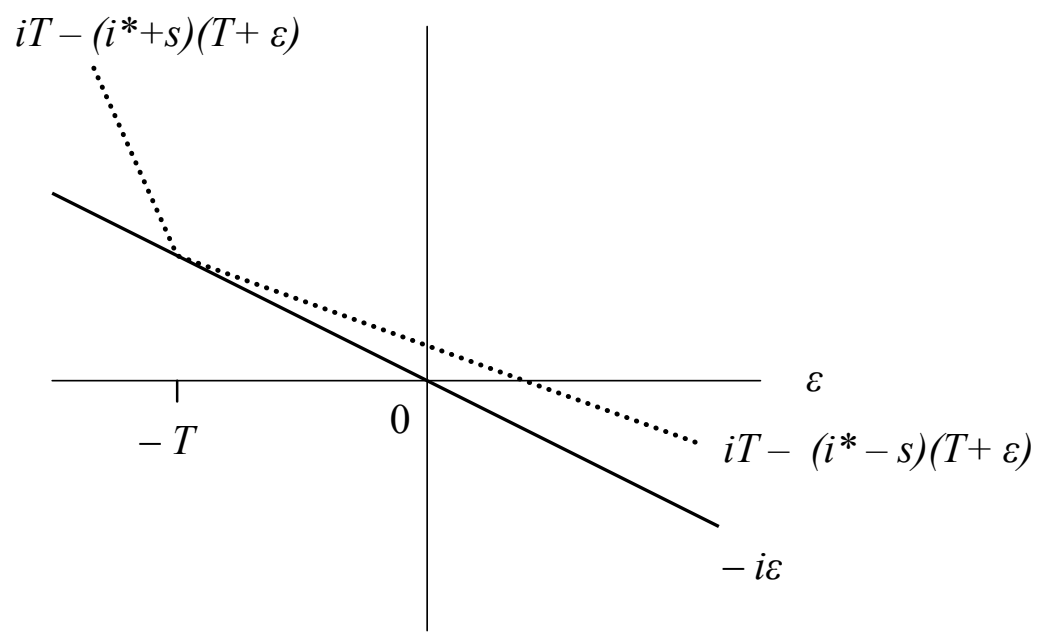

Distribution of Account Shock

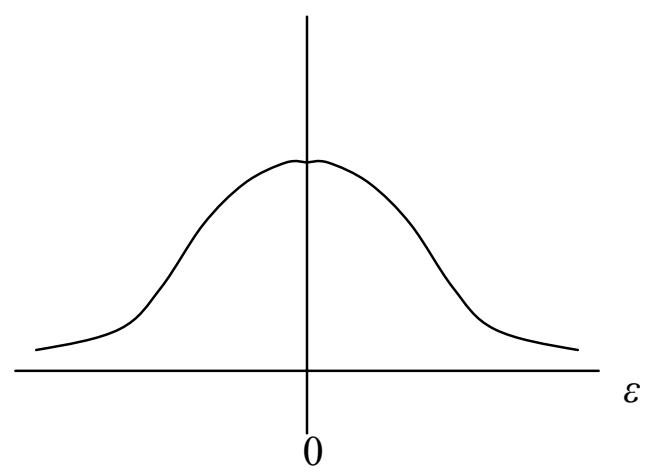

Note: The bank chooses the amount $T$ to borrow (or withhold) from the market at interest rate $i$. After an account shock, its end-of-day balance at the central bank is $T+\varepsilon$. It earns $i^{*}-s$ on any positive balances or pays $i^{*}+s$ on any account overdraft. With full information, as long as $i^{*}-s<i<i^{*}+s$, the bank chooses $T=-\varepsilon$ and its cost is $-i \varepsilon$. But knowing only the distribution of $\varepsilon$, it chooses $T$ to minimize the expected opportunity costs given by the probability-weighted vertical distances between the dotted and solid lines on the left. 
$<A 1>$ A representative, competitive bank is risk-neutral at the margin.

$<A 2>$ Loans are freely available from the central bank, as perfect substitutes for borrowings from the private market, at an interest rate of $i^{*}+s$. End-of-day account overdrafts are booked as loans at that interest rate.

$<A 3>$ Balances left overnight in an account at the central bank are perfect substitutes for lending in private markets and earn interest at the rate of $i^{*}-s$.

When choosing its target account balance, $T$, the private bank's information set is:

$I_{0}: i^{*}, s$, the market rate $i$, and the distribution of the account balance shock, $F(\varepsilon)$, with $E(\varepsilon)=0$.

If the bank had full information, it would set $T=-\varepsilon$, given $i^{*}-S<i<i *+s$. Then its end-of-day balance at the central bank would be zero and its net funding cost would be minimized at $-i \varepsilon$. Without knowing $\varepsilon$, the bank chooses $T$ to minimize two types of expected costs: the opportunity cost of holding a positive balance in its account at the central bank, relative to lending funds in the market, given by $i-(i *-s)$, and the loss, in the case of overdrafts, on borrowing from the central bank rather than from the market, given by $i^{*}+s-i$. Formally, the bank's problem is:

$$
\min _{T} \int_{I_{0}} \int_{-T}^{\infty}\left(i-i^{*}+s\right)(T+\varepsilon) d F(\varepsilon)-\int_{-\infty}^{-T}\left(i^{*}+s-i\right)(T+\varepsilon) d F(\varepsilon)
$$

The first order condition may be written in the form:

$$
F\left(-T^{*}\right)=\frac{1}{2}+\frac{i-i^{*}}{2 s} .
$$

where $T^{*}$ is the optimal choice. Consider interpretations of [2] under the assumption of symmetric or Gaussian distributions:

$<A 4>$ The distribution of the account shock, $F()$, is symmetric with a zero mean.

$<A 4^{\prime}>$ The account shock has a normal distribution with zero mean and variance $\sigma^{2}$. 
If the market interest rate equals the central bank's desired rate, then inspection of equation [2] indicates that $F\left(-T^{*}\right)=\frac{1}{2}$, and for a zero-mean symmetric distribution, $<\mathrm{A} 4>$, this can occur only if banks target a zero balance $\left(T^{*}=0\right)$, as noted by Woodford (2001). The zerobalance target at $i=i^{*}$ is unaffected by changes in $i^{*}$ or in the spread, $s$, as long as the policy target remains at the midpoint between the central bank's lending and deposit rates.

$$
\text { Under }<\mathrm{A}^{\prime}>, F\left(-T^{*}\right)=N\left(\frac{-T^{*}}{\sigma}\right), \text { where } N() \text { is the cumulative standard normal }
$$

distribution function, and the interest sensitivity of reserve demand is:

$$
\frac{\partial T^{*}}{\partial i}=\frac{\partial T^{*}}{\partial\left(i-i^{*}\right)}=\frac{-1}{2 \sin \left(\frac{T^{*}}{\sigma}\right)}<0
$$

with $n$ () denoting the standard normal density. The ceiling and floor properties emerge: As the overnight rate approaches the central bank's deposit rate $\left(i \rightarrow i^{*}-s\right)$, equation [2] indicates that $T^{*} \rightarrow \infty$ and [3] reveals that the demand curve flattens out. The elasticity also becomes infinite as the overnight rate approaches the central bank's lending rate of $i^{*}+s$ and $T^{*} \rightarrow-\infty$. The responsiveness of target balances to the spread can be written as:

$$
\frac{\partial T^{*}}{\partial s}=\frac{1-2 N\left(\frac{T^{*}}{\sigma}\right)}{2 \operatorname{sn}\left(\frac{T^{*}}{\sigma}\right)}
$$

A wider spread of lending and deposit rates around the central bank's desired interest rate implies a generally steeper demand curve, as [4] is positive if $T^{*}<0$ and negative if $T^{*}>0$. It is also readily shown that the elasticity of $T^{*}$ with respect to $\sigma$ is unity.

Exhibit 2 plots reserve demand under normal distributions for account shocks. The left panel shows the steepening of the demand function with an increase in the spread. The right panel depicts the flattening of the curve in response to an increase in uncertainty about 


\section{Exhibit 2: SIMPLE TUNNEL MODEL}

\section{Demand for Central Bank Balances}
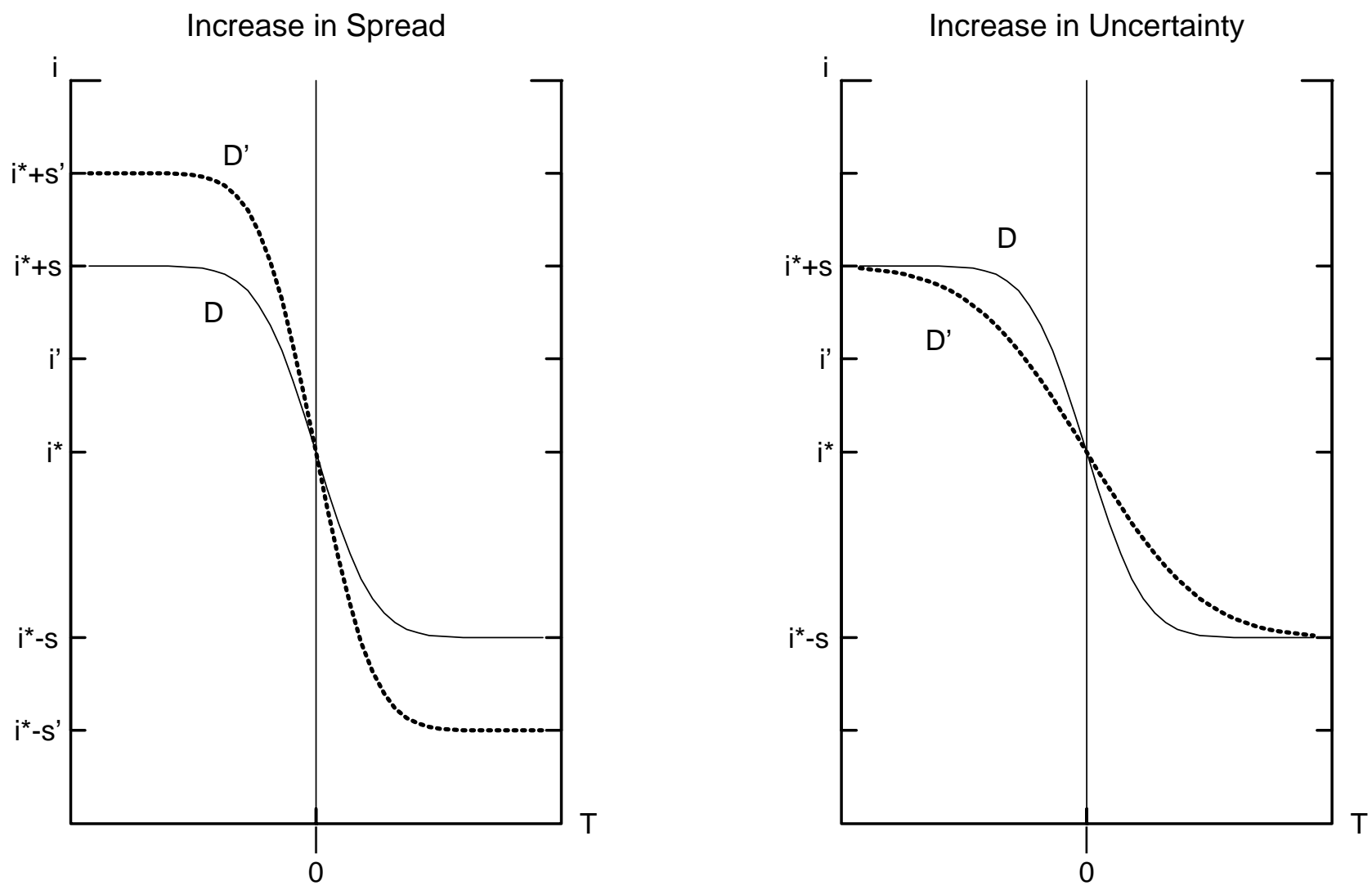

Note: $i$ is the overnight market interest rate, $i^{*}$ is the central bank's desired overnight rate, $i^{\star}+s$ is the central bank's lending rate, $i^{*}-s$ is the central bank's interest rate on account balances, $\mathrm{D}$ is the demand function for balances by a representative bank, indicated by the quantity targeted, $\mathrm{T}$, on the horizontal axis, while uncertainty is measured by the perceived standard deviation of the end-of-day account balance shock (it doubles in the dotted line in the right panel). If the central bank's desired rate were i' instead of $i^{*}$, the opportunity costs of overdrafts and excess balances would be asymmetric, and the aggregate quantity demanded at the desired rate would vary over time with changes in the account uncertainties perceived by those banks trading overnight funds. 
the end-of-day account balance. ${ }^{5}$ In both cases, the vertical intercept, midway between the central bank's deposit and lending interest rates, is a pivot point. These results highlight the importance for the central bank to set a policy target at an interest rate that equalizes the opportunity costs of overdrafts and excess balances. The account uncertainty perceived by the private bank, $\sigma$, would vary across banks and over time for the same bank. As individual bank account uncertainty and the mix of banks in the market varied from day to day, the shape of the aggregate reserve demand curve would change. Nevertheless, if the central bank set its desired interest rate at the midpoint between its deposit and lending rates, the aggregate quantity of nonborrowed reserves it needed to supply to hit that desired rate would be constant over time at zero. By contrast, a central bank that set its desired interest rate at another point, such as $i^{\prime}$ in Exhibit 2, would have re-estimate the demand curve day by day to determine the quantity of reserves it should supply to hit its policy target.

\section{Nonborrowed Reserve Supply}

Of course, arranging for the aggregate supply of nonborrowed reserves to equal zero on a daily basis is also a non-trivial task. Autonomous movements of items on the central bank's balance sheet, such as withdrawals of currency by commercial banks, the movement of funds by the Treasury between the banking system and its account at the central bank, and the implicit provision of central bank liquidity through float arising from check clearings, would still need to be predicted and offset by open market operations or other means.

We briefly explore the role of nonborrowed reserve supply in this model. To develop the aggregate demand for such reserves, we first invert equation [2]:

$$
T^{*}=-F^{-1}\left(\frac{1}{2}+\frac{i-i^{*}}{2 s}\right),
$$

where $F^{-1}()$ is the inverse of the distribution function. Then we sum across individual banks, indexed by $j$ :

5 Poole (1968) first pointed out the increased elasticity of reserve demand owing to greater dispersion in the distribution of account shocks. His model, which did not allow for overnight overdrafts, employed a bounded support for the distribution. 


$$
D=\sum_{j} T_{j}^{*}=-\sum_{j} F_{j}^{-1}\left(\frac{1}{2}+\frac{i-i^{*}}{2 s}\right)=-N^{-1}\left(\frac{1}{2}+\frac{i-i^{*}}{2 s}\right) \sum_{j} \sigma_{j},
$$

where the last equality follows for normal distributions of account uncertainties.

Realized account shocks arising from the failure of expected payments to clear between private banks would aggregate to zero across banks. However, the private bank's account shocks owing to transactions with the central bank directly or with central bank account holders that do not participate in the interbank market (such as the Treasury or other official institutions) would affect the aggregate quantity of nonborrowed reserves in the interbank market. Let $\sigma_{c b}$ represent unconditional uncertainty about aggregate reserve supply by the central bank. It is not necessarily the case that $\sigma_{c b}<\sum_{j} \sigma_{j}$. The volatility of aggregate nonborrowed reserves depends importantly on the quality of the central bank's forecast of autonomous items on its balance sheet at the time it intervenes to adjust aggregate reserve supply. If that intervention takes the form of a repurchase agreement (repo), the central bank may undertake it in the morning, when repo markets are more liquid, as in the United States. The resulting volatility in nonborrowed reserve supply may be sizable relative to the uncertainties of private banks regarding their account positions after the completion of market trading on the day. ${ }^{6}$ The ratio of these two types of uncertainties is a key factor in the distribution of the market interest rate in this model:

$$
\text { Central/Private Bank Uncertainty } \equiv \frac{\sigma_{c b}}{\sum_{j} \sigma_{j}},
$$

Exhibit 3 depicts histograms of the distribution of market interest rates under different assumptions for the ratio in [7]. The larger the ratio, the fatter the tails of the resulting distribution of overnight interest rates.

\footnotetext{
${ }^{6}$ This over-simplifies actual information flows and market frictions late in the day. Account uncertainty is likely reduced to fairly low levels for most banks by the end of trading. However, the shocks modeled here could reflect unexpected late-day payments that occur even before the market closes, if the bank is unable to borrow or lend in sufficient quantities in the late-day market to offset such shocks owing to line limit constraints.
} 
Exhibit 3: TUNNEL MODEL

Simulated Histograms of Market Rates

Central/Private Bank Uncertainty $=1 / 10$

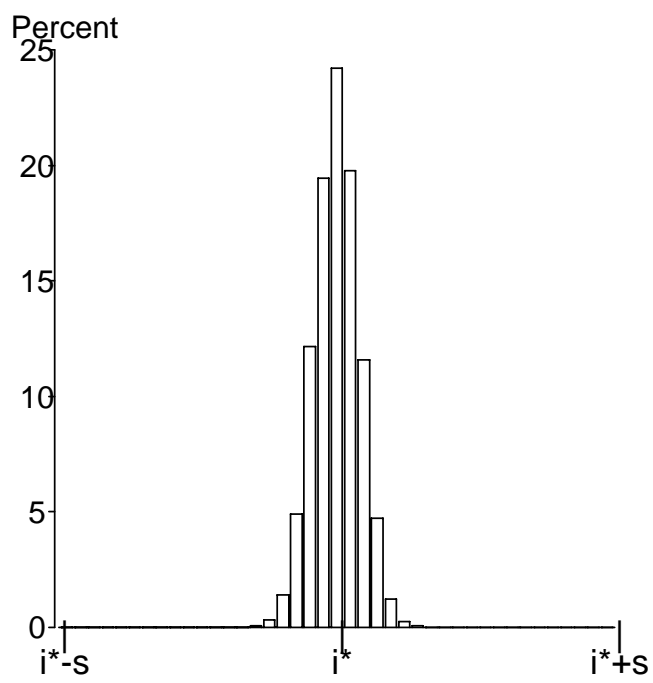

Central/Private Bank Uncertainty $=1 / 1$

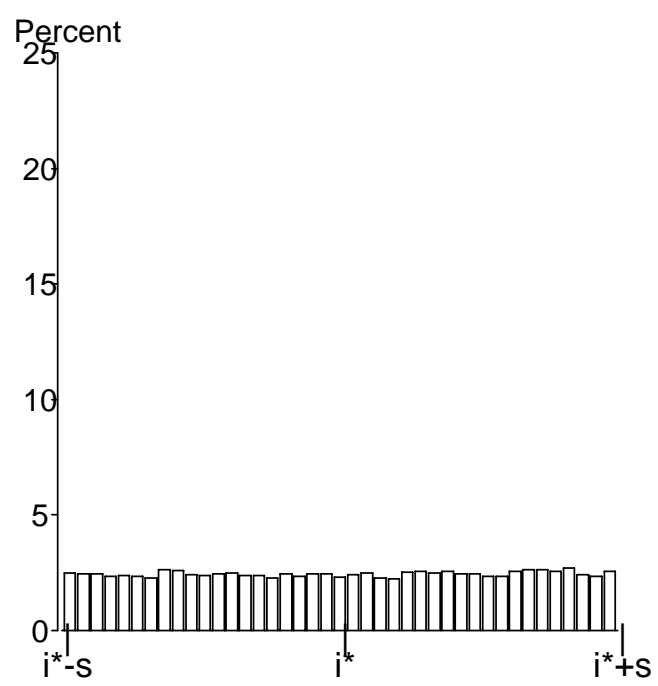

Central/Private Bank Uncertainty $=1 / 2$

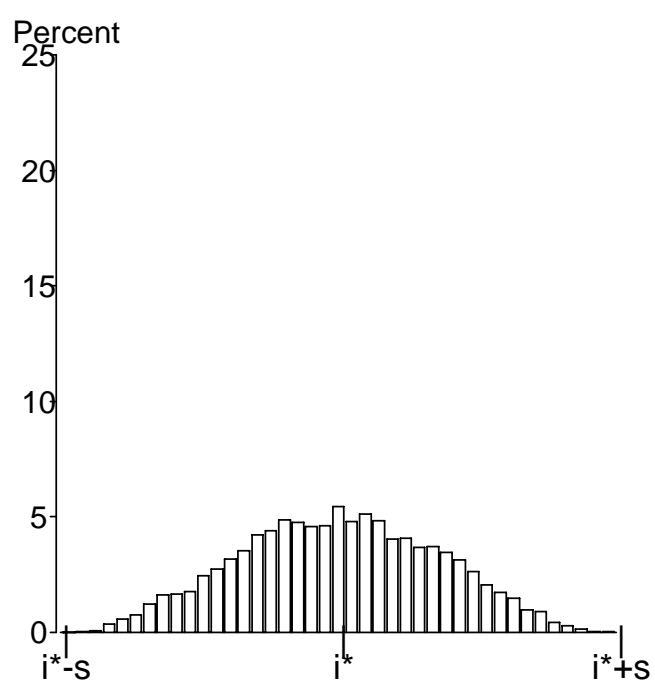

Central/Private Bank Uncertainty $=2 / 1$

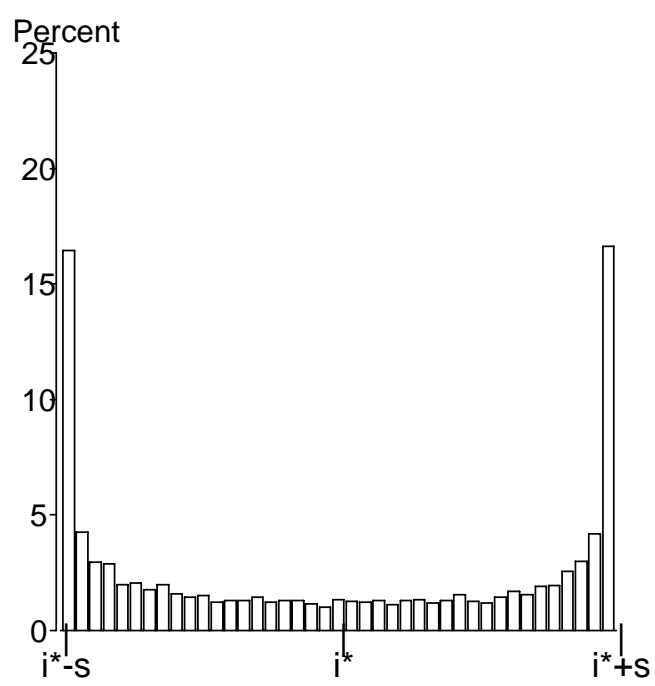

Note: Each graph is based on 10,000 draws of shocks to the central bank's aggregate supply of reserves. 


\section{The Elasticity of Demand}

The elasticity of demand is another key issue for policy implementation. In general, if reserve demand is highly elastic, the central bank's job is easy, as errors in assessing reserve demand or in estimating autonomous factors in its own balance sheet would then have little impact on overnight interest rates. By contrast, if the demand for reserves is inelastic, errors in the supply of nonborrowed reserves by the central bank have substantial effects on the overnight market interest rate.

In the model, demand is highly elastic near the ceiling and floor interest rates. Goodfriend (2002) proposed that a central bank could take advantage of the elastic region for interest rates near the central bank's deposit rate by setting the deposit rate equal to its desired market rate and then supplying a sufficient quantity of reserves to drive the market rate to that floor. However, if private rates are sustained at one of the boundaries of the tunnel, trading in the interbank market may dry up, which the central bank might not find desirable.

A key disadvantage of the tunnel model is that the slope of the demand curve is steepest at the central bank's desired interest rate of $i^{*}$ (and it is actually the slope rather than the elasticity per se that matters for the volatility of the overnight rate). In the above setup, for instance, with a symmetric distribution, the demand curve slope peaks at $\frac{\partial i}{\partial T^{*}}=-s$ when $i=i^{*}$.

This elasticity (or slope) problem becomes especially important in light of issues related to the substitutability of market transactions for central bank loans and deposits. For instance, interbank loans are generally unsecured, but collateral must be posted to borrow from a central bank. Thus, the cost of borrowing from the central bank would actually be $i^{*}+s$ plus the cost of providing collateral. Any stigma effects in borrowing from the central bank would raise the costs further. Moreover, the market rate equivalent to a deposit at the central bank would actually be $i^{*}-s$ plus a private sector credit risk premium. Such considerations would imply an asymmetry in the opportunity costs around the central bank's desired interest rate. The resulting demand curve would lie above and to the right of the one in the model, but its exact position might vary over time with credit risk perceptions and the 
opportunity costs of collateral. ${ }^{7}$ Because of the steepness of the reserve demand curve near the desired interest rate in this model and potential difficulties in estimating the location of the demand curve, particularly in more complex money markets with heterogeneous participants, a central bank might wish to assess the role of reserve requirements in a tunnel system, to which we now turn.

\section{Time-Averaged Balance Requirements}

This section develops a tunnel model in which a representative bank is required to hold an average balance at the central bank over a multi-day reserve maintenance period. For intuition, consider first the previous one-day tunnel model with no uncertainty. If the market interest rate were between the central bank deposit and lending rates, the private bank would hold a zero balance. If the market rate began moving above the central bank's lending rate, a bank could arbitrage by borrowing from the central bank and selling into the market. If the market rate began moving below the central bank's deposit rate, a bank could arbitrage by borrowing from the market to make deposits at the central bank. Thus, the demand curve would be a single step function as in the left panel of Exhibit 4.

Now suppose that the representative bank, again with no account position uncertainties, is subject to an average reserve requirement of $R$ over a two-day maintenance period, which the bank is compelled to meet. The second day is the reserve "settlement day," and the interest rate on that day, denoted by $i_{S}$, is the only uncertainty as of day one. A risk neutral bank would then fund the entire reserve requirement of $2 R$ on pre-settlement day, if the interest rate on that day, $i_{P}$, were less than the expected market rate on settlement day, $E\left(i_{S}\right)$. If instead $i_{P}>E\left(i_{S}\right)$, the bank would fund the entire requirement the second day. Thus, the demand curve on day one would be a two-step function as shown on the right in Exhibit 4. Interior solutions on pre-settlement day (with $0<T_{P}<2 R$ ) would all occur at a market rate equal to the expected settlement day interest rate. This is the martingale property employed within a maintenance period by Bartolini/Bertola/Prati (2002) and others. Thus,

\footnotetext{
7 Unexpected implicit asymmetries became evident after implementation of a tunnel system by the Bank of Canada. Despite using standing facilities to create an apparently symmetric spread of 25 basis points above and below the target rate, the central bank found it had to provide a positive level of aggregate reserves to achieve its desired market rate. See Woodford (2001), page 38 .
} 
(Demand Curves for Central Bank Balances)

\section{NO ACCOUNT BALANCE UNCERTAINTY}

One-Day Model

(no required balance)

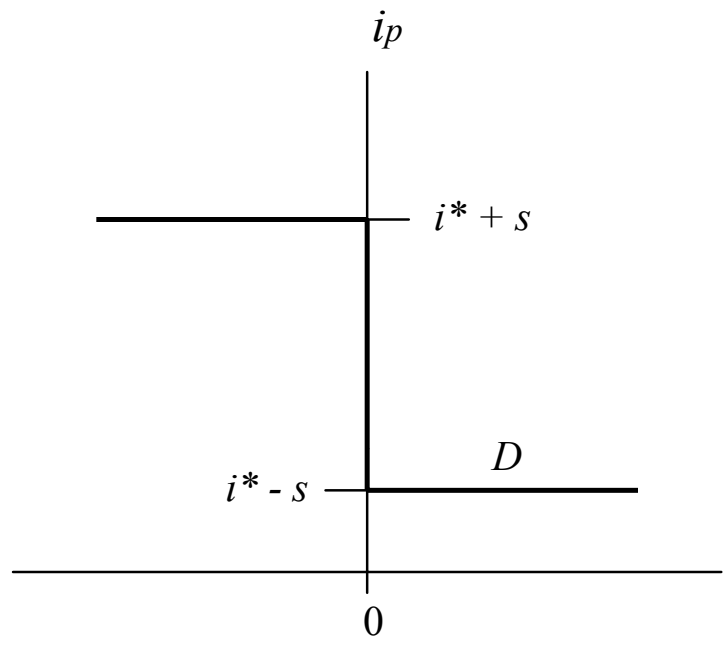

First Day of Two-Day Model

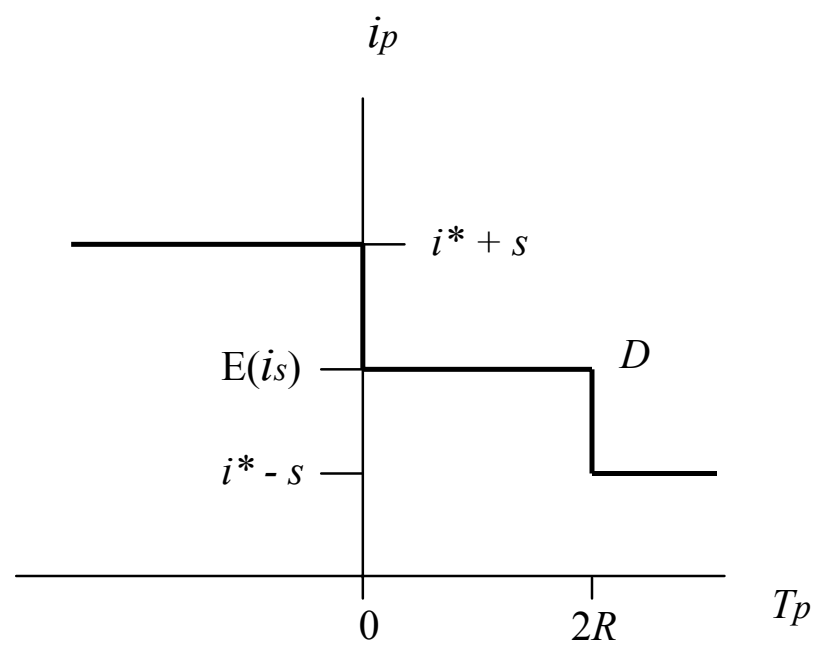

Note: $R$ is the two-day average reserve requirement, $i^{*}$ is the central bank's desired overnight rate, $i^{*}+s$ is its lending rate, $i^{*}-s$ is its interest rate on deposit balances, and the market interest rate is represented by $i_{p}$ on pre-settlement day and $i_{s}$ on settlement day. 
the period-average balance requirement has increased the elasticity of demand at an interior value for the interest rate. If market participants were confident that the central bank could hit its desired interest rate on settlement day, the demand curve on pre-settlement day would be very elastic at that same rate.

Now we develop a model with uncertainty about daily account positions and two-day balance requirements. Additional assumptions are:

$<A 5>$ Reserve requirements are assessed against deposits in a previous period and are met by holding minimum average balances at the central bank over a two-day maintenance period. Shortfalls from requirements are made up through borrowing from the central bank at the standard lending rate of $i^{*}+s$ or, equivalently, through a penalty charge at that rate. Account shocks on settlement day, denoted by $\xi$, may have a different distribution, $G()$, than account shocks on pre-settlement day.

With lagged reserve requirements, account shocks that change the private bank's reservable deposits do not affect its reserve requirement within the same period. The level of uncertainty on settlement day is allowed to differ from that on a pre-settlement day, reflecting the empirical results of Hamilton (1996) and others. Note also that in this model, funds borrowed from the central bank to cover an overdraft can be used to meet reserve requirements. With a minimum daily account balance of zero after borrowings, a zero period-average requirement is therefore equivalent to the absence of reserve requirements. ${ }^{8}$

Consider initially the problem on settlement day, assuming that the private bank has a remaining balance requirement of $b$. The bank may purchase balances from the market at the settlement day interest rate, $i_{S}$, and it earns $i^{*}-s$ on required or excess balances held at the central bank. It chooses a target balance $T_{S}$ with the information set:

$I_{s}: \quad i^{*}, s, G(\xi), E(\xi)=0$, the settlement day market interest rate, $i_{S}$, and the remaining required balance as of settlement day, $b$.

\footnotetext{
8 If borrowings undertaken to bring an overdrafted account up to a zero balance did not count towards reserve requirements (as is the case at the Federal Reserve), a separate reserve deficiency charge would be needed because of possible overdrafts on settlement day. The symmetry of a tunnel model and its advantage for predicting the aggregate quantity of reserves demanded at the desired interest rate would then generally be lost.
} 
The bank's settlement day cost minimization problem is then:

$$
\min _{T_{S}}\left(i_{S}-i^{*}+s\right) b+\int_{b-T_{S}}^{\infty}\left(i_{S}-i^{*}+s\right)\left(T_{S}+\xi-b\right) d G(\xi)+\int_{-\infty}^{b-T_{S}}\left(i^{*}+s-i_{S}\right)\left(b-T_{S}-\xi\right) d G(\xi)
$$

The first term is the net cost of borrowing from the market to meet the remaining balance requirement, the first integral is the opportunity cost of holding excess balances, and the last integral is the net cost of borrowings from the central bank, rather than the market, to meet the requirement. If $b=0,[8]$ becomes equivalent to [1]. Similar to [2], the Euler condition associated with $[8]$ is:

$$
G\left(b-T_{S}^{*}\right)=\frac{1}{2}+\frac{i_{S}-i^{*}}{2 s} .
$$

If $i_{S}=i^{*}$ and $G$ is symmetric around the mean of zero, the bank targets its remaining requirement $\left(T_{S}^{*}=b\right)$. The settlement day demand function, plotted in Exhibit 5 for a normal distribution, is merely a rightward shift of the demand function in Exhibit 2, with the pivot point at $b$ rather than at zero. The tunnel framework provides an advantage for central bank policy implementation even in the presence of reserve requirements, as the aggregate demand for excess reserves on settlement day is zero at the desired interest rate, irrespective of the account uncertainties that private banks perceive.

To move toward development of the pre-settlement day demand function, note first that:

$$
\frac{\partial T_{S}^{*}}{\partial b}=1
$$

or in other words, $b-T_{S}^{*}$ is independent of $b$. Thus, we can write the optimal value of $b-T_{S}^{*}$ as a function of $i_{S}$ and other parameters:

$$
b-T_{S}^{*} \equiv k\left(i_{S}, i^{*}, s\right)=G^{-1}\left(\frac{i_{S}-i^{*}}{2 s}+\frac{1}{2}\right) .
$$


Exhibit 5: Time-Averaged Balance Requirements

Demand on Settlement Day

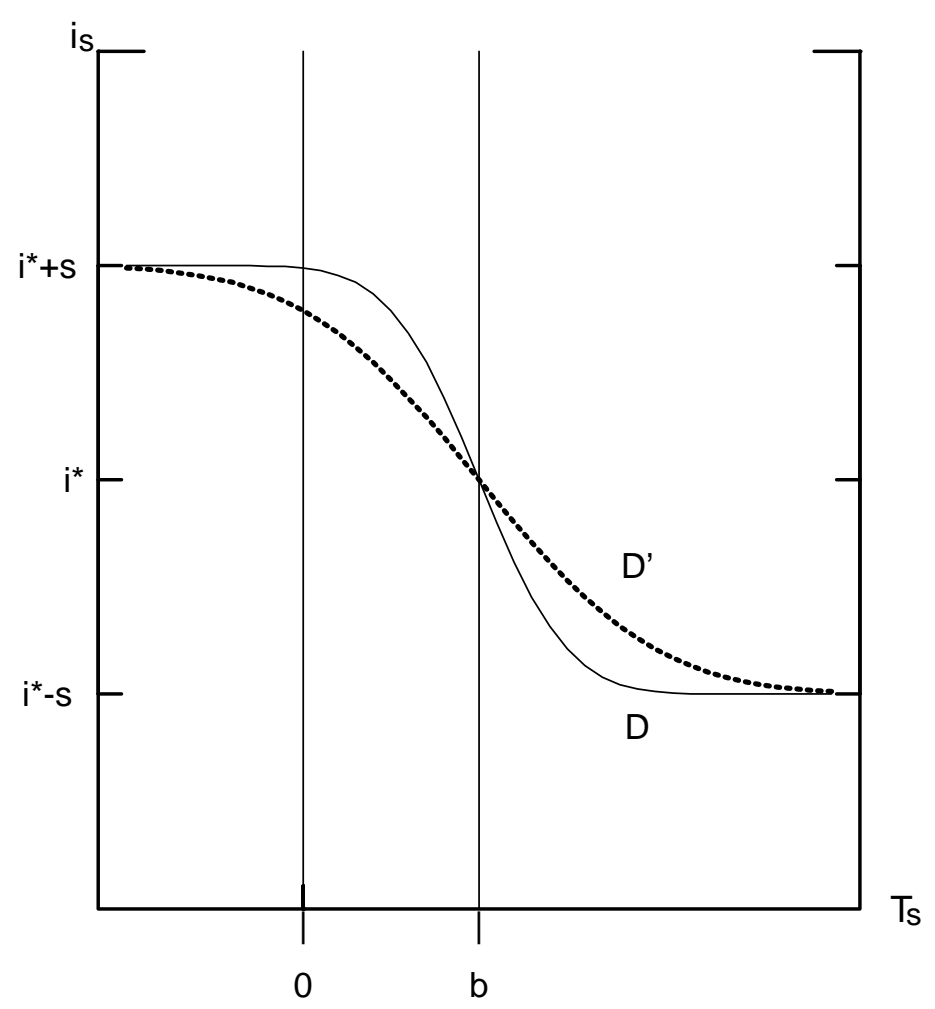

Note: The dotted line, D', assumes 4 times more account uncertainty. 
Substituting $T_{S}^{*}$ into the objective function gives the expected cost function with information set $I_{S}$ :

$$
\begin{gathered}
V\left(T_{S}^{*} \mid I_{S}\right)=\left(i_{S}-i^{*}+s\right) b+s \int_{k\left(i_{S}, i^{*}, s\right)}^{\infty} \xi d G(\xi)-s \int_{-\infty}^{k\left(i_{s}, i^{*}, s\right)} \xi d G(\xi) \\
=\left(i_{S}-i^{*}+s\right) b+K\left(i_{S}, i^{*}, s\right)
\end{gathered}
$$

where the upper case $K\left(i_{S}, i^{*}, s\right)$ is defined as the last two terms on the first line of [12]. ${ }^{9}$ It reflects the expected opportunity cost of being above or below the reserve requirement with information set $I_{S}$.

In this model, intertemporal arbitrage is limited by the risk of daily account overdrafts. Therefore, the pre-settlement day interest rate, $i_{P}$, may differ from the expected settlement day rate. The pre-settlement day information set, $I_{p}$, does not include knowledge of either the remaining balance requirement on settlement day, $b$, or the settlement day interest rate, $i_{S}$ :

$I_{p}: i_{P}, i^{*}, s, F(\varepsilon), G(\xi)$, and $E(\varepsilon)=E(\xi)=0$.

The value of $b$ is determined after realization of the account shock on pre-settlement day. With a daily average requirement of $R$ and denoting the end-of-day account balance on presettlement day by $T_{P}+\varepsilon$, the value of $b$ is:

$$
b=\left\{\begin{array}{cl}
2 R, & \text { if } T_{P}+\varepsilon \leq 0 \\
2 R-T_{P}-\varepsilon, & \text { if } 0 \leq T_{P}+\varepsilon \leq 2 R, \\
0, & \text { if } T_{P}+\varepsilon \geq 2 R .
\end{array}\right.
$$

9 If $\xi$ is normally distributed with mean zero and variance $\varphi^{2}$, then $K\left(i_{S}, i^{*}, s\right)=2 s \varphi n\left(\frac{N^{-1}\left(\frac{1}{2}+\frac{i_{S}-i^{*}}{2 s}\right)}{\varphi}\right)$. 
Let $e \equiv E_{I_{P}}\left(i_{S}\right)-i *$ represent the private bank's expectation on pre-settlement day of the deviation of the market rate from the central bank's desired interest rate on settlement day. Then, ignoring discounting between the first and second day of the maintenance period, and using [12] and [13], the pre-settlement day target balance is found from:

$$
\begin{aligned}
& \min _{T_{P}} \int_{-T_{P}}^{\infty}\left(i_{p}-i^{*}+s\right)\left(T_{P}+\varepsilon\right) d F(\varepsilon)-\int_{-\infty}^{-T_{P}}\left(i^{*}+s-i_{p}\right)\left(T_{p}+\varepsilon\right) d F(\varepsilon) \\
& +\quad 2 R(e+s) F\left(-T_{P}\right)+(e+s) \int_{-T_{P}}^{2 R-T_{P}}\left(2 R-T_{P}-\varepsilon\right) d F(\varepsilon)+E_{I_{p}}\left(K\left(i_{S}, i^{*}, s\right)\right) .
\end{aligned}
$$

The first line of [14] is equivalent to [1]. The first term on the second line is the expected net cost, with information set $I_{p}$, of meeting the period's entire requirement $(2 R)$ on settlement day, times the probability of having a negative or zero account balance on day one. The middle term on the second line is the expected net cost of completing the period-average requirement on settlement day if that requirement has been partially met before settlement day. The final term reflects uncertainty under $I_{p}$ about the settlement day interest rate, but it is unaffected by the pre-settlement day decision.

The Euler condition is:

$$
i_{p}-i^{*}+s+(e-s) F\left(-T_{P}^{*}\right)-(e+s) F\left(2 R-T_{P}^{*}\right)=0 .
$$

If the pre-settlement day market interest rate is at the central bank's desired rate and expected to be there again on settlement day, so that $i_{p}=i^{*}$ and $e=0$, this condition simplifies to:

$$
1-F\left(-T_{P}^{*}\right)=F\left(2 R-T_{P}^{*}\right),
$$

and if $F$ is symmetric around the mean of zero, the bank targets the daily average reserve requirement $\left(T_{P}^{*}=R\right)$ on pre-settlement day. With a normal distribution, the key comparative statics are: 


$$
\begin{aligned}
& \frac{\partial T_{p}^{*}}{\partial R}=\frac{2}{1+\left[\frac{s-e}{s+e}\right] \frac{n\left(T_{p}^{*} / \sigma\right)}{n\left(\frac{2 R-T_{p}^{*}}{\sigma}\right)}}>0 \\
& \frac{\partial T_{p}^{*}}{\partial i_{p}}=\frac{-1}{(s+e) n\left(\frac{T_{p}^{*}}{\sigma}\right)+(s-e) n\left(\frac{2 R-T_{p}^{*}}{\sigma}\right)}<0,
\end{aligned}
$$

where the signs follow as long as the market rate is expected to remain within the tunnel $(s>e)$. Under normality, reserve demand curves for two different expected settlement day interest rates are depicted in the top left panel of Exhibit 6. Demand is very elastic near the expected settlement day interest rate for a range of values of $T_{P}^{*}$ around the daily average requirement. As shown elsewhere on Exhibit 6, the flat region of the demand curve would expand with a larger reserve requirement or lower account uncertainty. To examine this region further, the Euler condition, [15], may be rewritten in the form of a deviation of the pre-settlement day interest rate from the expected interest rate on settlement day:

$$
i_{P}-E_{I_{P}}\left(i_{S}\right)=(s-e) N\left(\frac{-T_{p}^{*}}{\sigma}\right)+(s+e)\left[N\left(\frac{2 R-T_{p}^{*}}{\sigma}\right)-1\right]
$$

where a normal distribution is assumed. The first term on the right includes the probability of an overdraft on pre-settlement day; it is close to zero when $T_{P}^{*}>2 \sigma$. The final bracket is close to zero when there is a high probability of having a positive remaining requirement on settlement day, which occurs when $T_{P}^{*}<2 R-2 \sigma$. The highly elastic region thus occurs where:

$$
2 \sigma<T_{P}^{*}<2 R-2 \sigma
$$

This line of reasoning could lead to suggestions for a longer maintenance period in order to engender a greater range of high elasticity. For instance, one might think that if the maintenance period were $m$ days instead of two days, the upper limit of the range would be 
Exhibit 6: Time-Averaged Balance Requirements

\section{Demand on Pre-Settlement Day}

Sensitivity to Expected

Settlement Day Interest Rate

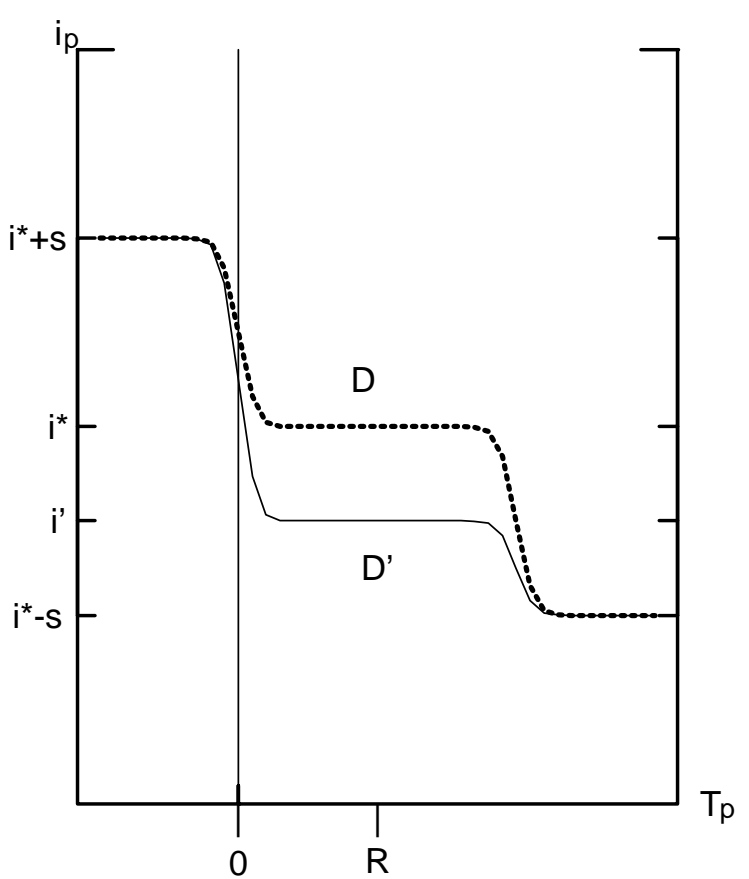

Increase in Requirements

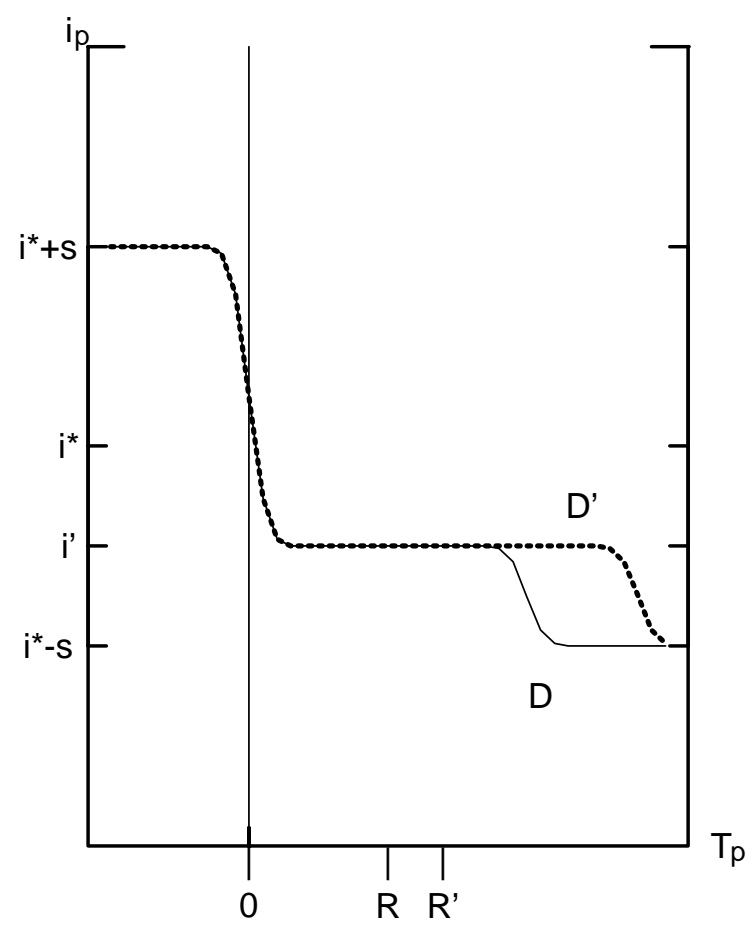

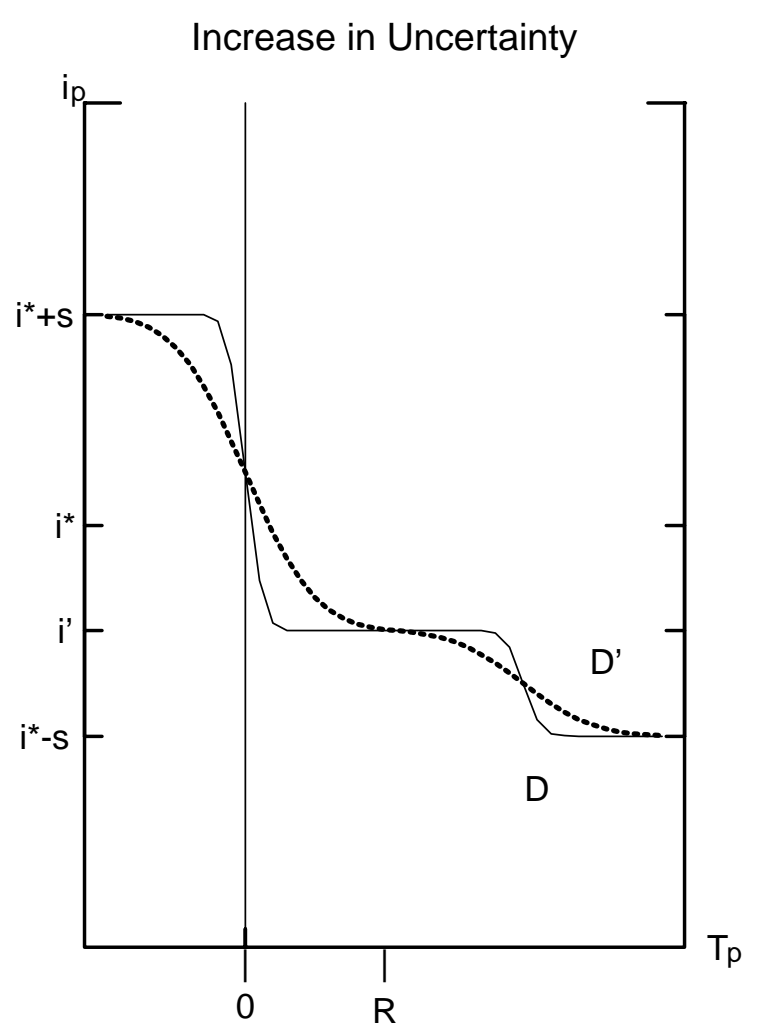

Notes:

Top left: the solid line assumes $E\left(i_{s}\right)=i^{\prime}$, the dotted line assumes $E\left(i_{s}\right)=i^{*}$.

Top right: the dotted line assumes a $40 \%$ larger reserve requirement.

Bottom left: the standard deviation of the account shock is $10 \%$ of $R$ for the solid line and $40 \%$ of $R$ for the dotted line. 
$m R-2 \sigma$. However, it is not clear that this particular inequality would characterize the elastic region with a longer reserve maintenance period, as closed-form solutions then become difficult to obtain. ${ }^{10}$ One common argument against long maintenance periods is that a number of banks may deliberately run behind on meeting requirements early in the period, expecting interest rates to fall; if these banks run into line limit constraints or other market frictions on settlement day, the volatility of the market rate that day could be more elevated. Moreover, with longer maintenance periods, arbitrage of expected changes in the central bank's target interest rate would be more frequent, which the central bank may not find desirable.

In sum, this model illustrates the advantages of both a tunnel system and periodaverage requirements. The symmetry of opportunity costs of the tunnel system allows the central bank to know that the aggregate demand for excess reserves on settlement day is zero, irrespective of possible time-varying account uncertainties at private banks. If this advantage is not outweighed by the problem of a steep demand curve at the desired interest rate, combined with imperfect substitutability of market transactions for central bank loans and deposits, the central bank should be aided in achieving its desired interest rate on settlement day. If the market expects that interest rate to be achieved on settlement day, intertemporal arbitrage induced by period-average requirements should help the same interest rate to be realized on pre-settlement days. However, these results occur in a model that abstracts from many details of the relationship of private banks to the central bank. For instance, for many private banks, the non-pecuniary aspects of their relationships to a central bank may loom larger than the explicit penalties for reserve deficiencies and overdrafts. The non-pecuniary considerations may vary across banks and over time for the same bank, making it difficult for the central bank to arrange for the symmetric opportunity costs called for in a tunnel model.

10 For instance, the first-order condition for the first day of a three day model, using subscripts for day of period, is:

$i_{1}-i^{*}+s\left\{1-2 F\left(-T_{1}\right)-\int_{-T_{1}}^{3 R-T_{1}} F\left(3 R-T_{1}-\varepsilon_{1}-T_{2}^{*}\right) d F\left(\varepsilon_{1}\right)\right\}=0$, where the optimal second day target, $T_{2}^{*}$, also depends on $3 R-T_{1}-\varepsilon_{1}$. 


\section{Voluntary Reserve Balance Requirements}

In the above model, period-average required balances aid the implementation of monetary policy, but they impose an implicit tax on private banks without conveying any direct benefits to them. The reserve tax could be largely eliminated through the payment of interest on required reserve balances at the market rate of interest. However, despite such interest payments, some banks might prefer to avoid reserve requirements in order to hold assets other than reserve balances. To eliminate completely the inefficiencies associated with reserve avoidance activities, a system of voluntary reserve requirements could be considered.

It is not difficult to imagine an institutional structure in which private banks might obtain some benefit from period-average required balances. A central bank might, for instance, seek to discourage overnight overdrafts by imposing a higher penalty on them than on reserve deficiencies. ${ }^{11}$ This penalty structure might reflect true economic costs in that overdrafts may be automatic and potentially unlimited, therefore involving greater risk than discount window loans, which may each require the signature of a central bank official to be approved. ${ }^{12}$ With overdrafts more costly than reserve deficiencies, a bank might voluntarily choose to establish a reserve requirement as a precaution against running overdrafts if the opportunity cost of holding reserves were not too high. Below, we explore such a voluntary reserve requirement regime in an analytically convenient, one-day model. The extension to a multi-day framework is a nonlinear simulation exercise.

In this model, the assumptions regarding central bank interest rates are as follows:

$<A 7>$ Reserve deficiencies are covered by discount window borrowings at rate $i^{*}$, account overdrafts incur a supplementary charge $w$, required reserve balances earn $i^{*}-v$, and

11 At the Federal Reserve, for example, the charge for overnight overdrafts is 4 percentage points above the effective federal funds rate on the day, but the penalty for a deficiency in meeting reserve requirements is only 1 percentage point above the primary credit rate, equivalent at present to 2 percentage points above the target funds rate. At the Bank of Japan, overnight overdrafts are charged 6 percentage points above the discount rate, while reserve shortfalls are charged only 3.75 percentage points above that rate. At the ECB, however, overnight overdrafts pay the marginal lending rate, while reserve shortfalls pay 2.5 percentage points higher. See Blenck et al (2001).

12 Also, at the Federal Reserve, while discount window loans must be collateralized, collateral may or may not be available to cover overdrafts. 
excess reserves earn $i^{*}-s$, where $0<v<s$. Overdrafts are assessed prior to the end-ofday settlement of discount window borrowings. ${ }^{13}$

In a symmetric tunnel version of this model, $w=s$, but symmetry is irrelevant here when the reserve requirement is positive, as shown below.

We write the bank's expected costs as a function of the reserve requirement, $R$, with $i$ again the known market rate when the target balance $T$ is chosen:

$$
\begin{aligned}
C(R)= & \min _{T}\left(i-i^{*}+v\right) R+\int_{R-T}^{\infty}\left(i-i^{*}+s\right)(T+\varepsilon-R) d F(\varepsilon) \\
& +\int_{-\infty}^{R-T}\left(i^{*}-i\right)(R-T-\varepsilon) d F(\varepsilon)-\int_{-\infty}^{-T} w(T+\varepsilon) d F(\varepsilon) .
\end{aligned}
$$

The first expression is the opportunity cost of holding required reserves and the first integral is the expected opportunity cost on excess reserves. On the second line, the first integral is the expected cost of borrowing from the central bank, rather than the market, to fulfill the reserve requirement, and the last term is the expected supplementary penalty for account overdrafts. The first order condition is:

$$
i-i^{*}+s\left[1-F\left(R-T^{*}\right)\right]-w F\left(-T^{*}\right)=0 .
$$

The response of reserve demand to a higher requirement is:

$$
\frac{\partial T^{*}}{\partial R}=\left[1+\frac{w}{s} \frac{f\left(-T^{*}\right)}{f\left(R-T^{*}\right)}\right]^{-1}>0 \text { and }<1
$$

To determine the bank's optimal choice of a reserve requirement, in principle, the optimal $T^{*}$ from [22] would be substituted into [21] to obtain a cost function, and the unconditional expectation of that cost function (across the distribution of market interest rates) would be taken. Finally, the optimal value of $R$ would be found by differentiating that unconditional

13 This last assumption limits the arbitrage of the overnight market interest rate with discount window borrowings because of the risk of overdrafts. Otherwise, $i^{*}$ would be the ceiling on the overnight market rate. 
cost function. For convenience, we take the derivative of [21] with respect to $R$ first; the Euler condition for $R$ is:

$$
E_{I_{u}}\left(\frac{\partial C}{\partial R}\right)=E_{I_{u}}\left(v+s\left[F\left(R^{*}-T^{*}\right)-1\right]\right)=0,
$$

where $T^{*}$ is also a function of $R^{*}$, given by [22], and $I_{u}$ is the unconditional information set. Equation [24] is a complex nonlinear function whose solution would depend on the bank's perceived distribution of the market interest rate. That distribution could have a variety of shapes, as suggested by Exhibit 3, reflecting in part the supply of nonborrowed reserves by the central bank. However, some conclusions may be drawn without specializing the model much further. First, with $T^{*}$ in [22] independent of $v$, given $R$, we can write the comparative static result:

$$
\frac{\partial R^{*}}{\partial v}=-\left[E_{I_{u}}\left(s f\left(R^{*}-T^{*}\right)\left[1-\frac{\partial T^{*}}{\partial R^{*}}\right]\right)\right]^{-1}<0,
$$

using [23]. Now we assume merely that banks expect the market interest rate to equal the central bank's desired rate on average:

$$
I_{u}: F(\varepsilon), E(i)=i^{*}
$$

Then, note that, if the opportunity cost of holding required reserves were equal to that for excess reserves $(v=s)$, [24] would require $F\left(R^{*}-T^{*}\right)$ to equal zero, which would imply an optimal reserve requirement of $-\infty$.

Next, observe that condition [24] can be written in an alternative form by substituting for $F\left(R^{*}-T^{*}\right)$ from [22]:

$$
E_{I_{u}}\left(\frac{\partial C}{\partial R}\right)=E_{I_{u}}\left(v+i-i^{*}-w F\left(-T^{*}\right)\right)=0
$$

If there were no average opportunity cost to holding reserves $(v=0),[24 \mathrm{a}]$ could be satisfied only if $F\left(-T^{*}\right)$ equaled zero, which would imply $T^{*} \rightarrow \infty$ requiring $R^{*} \rightarrow \infty$. 
Finally, we can demonstrate the existence of interior solutions:

Proposition: For small positive values of $v$, the optimal choice of a reserve requirement in problem [21] is positive and finite.

Proof: First note that the second order condition for $R^{*}$ to be a minimum holds:

$$
E_{I_{u}}\left(f\left(R^{*}-T^{*}\right)\left[1-\frac{\partial T^{*}}{\partial R^{*}}\right]\right)>0,
$$

using [23]. Next, note that, when $R=0$, the left hand side (LHS) of [24], after substituting for $F\left(0-T^{*}\right)$ from [22] and taking expectations, is negative when:

$$
v<\frac{s w}{s+w} .
$$

Thus, for positive values of $v$ below this threshold, $R^{*}$ must be greater than zero. Finally, because $R-T^{*}$ is increasing in $R$ (from [23]), so is $F\left(R-T^{*}\right.$ ). As $R \rightarrow \infty$, the LHS of [24] goes to $v$. Thus, the LHS of [24] must hit zero at a finite positive value for the voluntary reserve requirement.

Demand for central bank balances in this model, assuming a normal distribution, is graphed in Exhibit 7. The demand curve without a reserve requirement, given by the dotted line in the left panel, is similar to that in Exhibit 2. Demand for balances equals zero at the midpoint between the interest rates on overdrafts and on deposits at the central bank. With a positive reserve requirement, the solid line, the demand curve has an elastic region at $i^{*}$, the interest rate on central bank borrowings excluding the supplementary overdraft charge; this result does not depend any symmetries, as indicated. The elastic region arises from the lower cost of a reserve deficiency than an account overdraft in this simple one-day model, in contrast to the multi-day model of the previous section, where the elasticity induced by reserve requirements was attributable to intertemporal arbitrage over the reserve-averaging period. As suggested by the right panel of Exhibit 7, the size of the chosen reserve requirement relative to the account balance uncertainty determines the width of the elastic region, but not its location. The central bank could control the optimal choice of reserve 


\section{Exhibit 7: VOLUNTARY RESERVE REQUIREMENTS}

\section{Demand for Central Bank Balances}
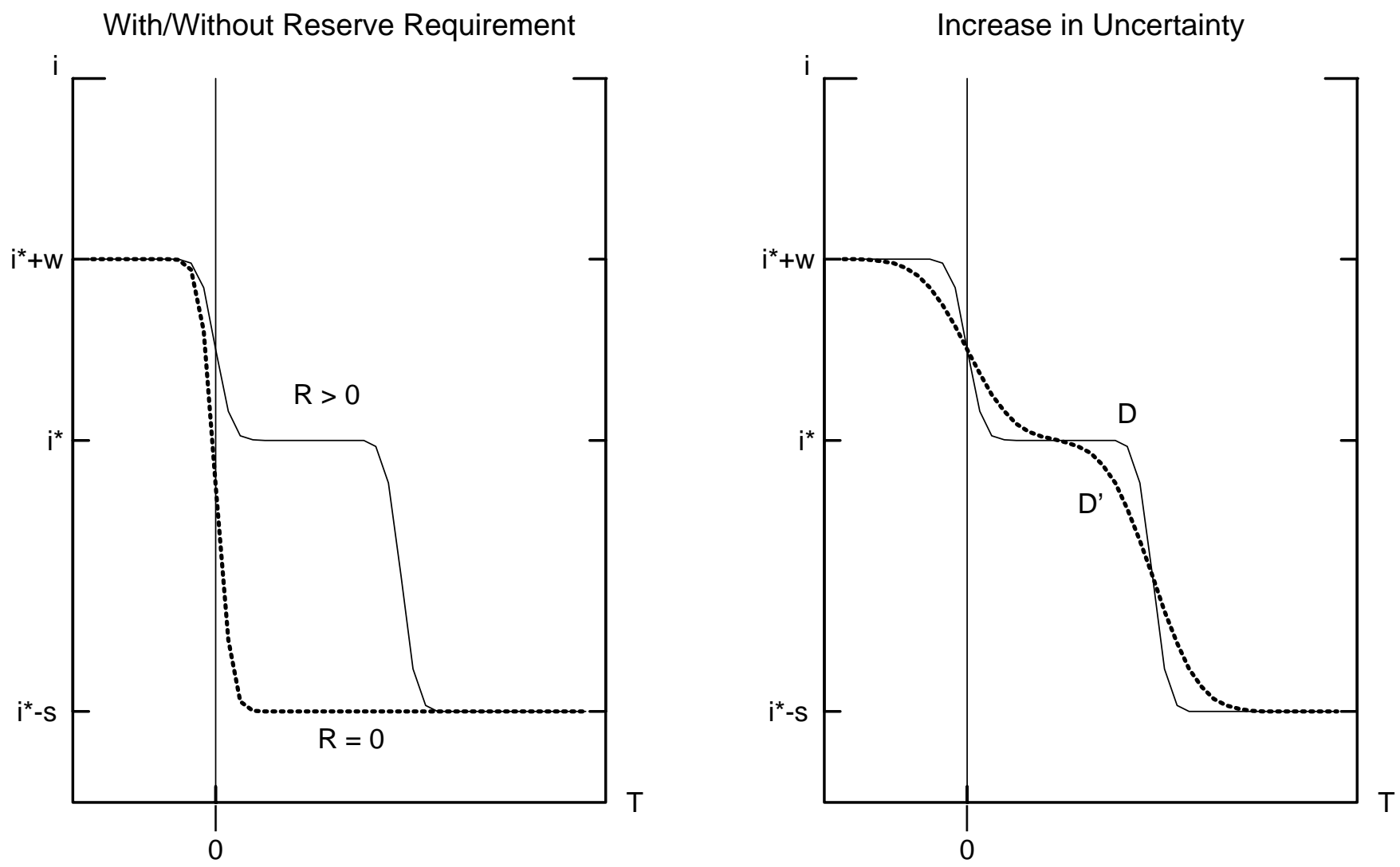

Note: $\mathrm{i}^{*}$ is the interest rate on borrowings to cover a reserve deficiency and $\mathrm{w}$ is the additional penalty for an overdraft. Deposits at the central bank earn $\mathrm{i}^{*}-\mathrm{s}$. On the left, the dotted line is without a reserve requirement, while the solid line in both panels assumes a voluntary reserve requirement that is 15 times the standard deviation of the account shock. The dotted line on the right is a requirement that is only 5 times the account shock standard deviation. The requirement choice depends on other parameters of the model that are not depicted here. 
requirement by adjusting the spread $v$. Presumably, the central bank would set the spread to ensure that it had sufficient required balances for the smooth implementation of monetary policy without absorbing too many funds from the banking system.

\section{Conclusion}

This paper began by analyzing a model for the implementation of monetary policy through standing facilities for lending and interest-bearing deposits at the central bank without reserve requirements. It identified a key benefit of such a tunnel system in facilitating estimates of the quantity of reserves demanded at central bank's desired interest rate. With symmetric spreads on lending and deposit interest rates around the central bank's desired rate, the aggregate quantity of reserves demanded at that interest rate is zero in a tunnel model, irrespective of the time-varying degree of account uncertainty faced by private banks. This symmetry feature could be useful to review even for central banks that do not pay interest on deposits but that implicitly move in and out of regions where spreads are symmetric owing to the proximity of their policy interest rates to the zero lower bound.

The paper also identified an important potential weakness of a tunnel regime in that the reserve demand curve is steepest at the central bank's desired interest rate. Errors in the supply of nonborrowed reserves by the central bank therefore could have sizable effects on market interest rates. Moreover, if market transactions were imperfect substitutes for central bank loans and deposits, it could be difficult for the central bank to arrange for the symmetric spreads needed in a tunnel model, and as a result, the quantity of reserves demanded at the desired interest rate might vary over time. Errors in estimating the position of the reserve demand curve could then also contribute to volatility of the market rate. Idiosyncratic aspects of an individual central bank's institutional environment could determine whether the benefits of a tunnel framework outweigh the potential disadvantages.

The paper also developed a model that combines a tunnel framework for policy implementation with period-average reserve requirements. Intertemporal arbitrage of expected future interest rates is limited in the model, because private banks subject to account position uncertainties incur penalties for overnight overdrafts. Nevertheless, reserve requirements induce a region of high elasticity of reserve demand on pre-settlement days at the expected interest rate on settlement day. The tunnel framework has a key advantage in 
such a regime in that the aggregate demand for excess reserves on settlement day equals zero, irrespective of the degree of account uncertainties perceived by private banks. Again, this advantage could be impaired by imperfect substitution of interbank loans for central bank loans and deposits.

While reserve requirements may be beneficial for the implementation of monetary policy, they have also been associated with financial market inefficiencies owing to the reserve avoidance activities of banks, and it may not be possible to rationalize such outcomes on the grounds of optimal taxation. One way of addressing the trade-off between the policy implementation benefits and the efficiency costs of reserve requirements would be for a central bank to pay a market rate of interest on required reserve balances. Another possible solution would be a system of voluntary reserve requirements. Elimination of compulsory reserve requirements likely would remove the incentives for reserve avoidance more completely than would the payment of interest on required balances. In the final model developed here, banks optimally choose to establish a reserve requirement in a tunnel regime in which the cost of overdrafts exceeds the cost of other borrowings from the central bank. This cost structure may reflect optimal pricing if overdrafts are riskier than other loans.

The paper pointed out the sensitivity of model results to some of the many complexities in the structure of the relationships of private commercial banks to the central bank. Changes in the parameters of such relationships, such as penalties for overdrafts and reserve deficiencies, non-pecuniary costs, collateralization policies, credit risk premia, the ability to use overdrafts to satisfy reserve requirements, the timing of central bank interventions in the market, and the availability of information regarding account positions may have significant effects on the structure and performance of any policy implementation regime. Moreover, the number and heterogeneity of institutions having accounts at the central bank and the market frictions arising from line limits or transaction costs may also importantly condition the functioning of the regime. The theoretical models presented in this paper are too stylized to be the basis for general recommendations appropriate for all central banks. Rather, they are intended to explore further a central bank's opportunity set regarding frameworks for the implementation of policy and, with other similar papers, could be used to stimulate additional work that takes account of more specialized institutional features of the policy implementation environment affecting individual central banks. 


\section{References}

Bartolini, Leonardo, Giuseppe Bertola, and Alessandro Prati, 2001, “Banks' Reserve Management, Transaction Costs, and the Timing of Federal Reserve Intervention," Journal of Banking and Finance, 25, pp. 1287-1317) ,2002, "Day-to-Day Monetary Policy and the Volatility of the Federal Funds Interest Rate," Journal of Money, Credit and Banking 34: 137-159.

Blenck, Denis, Harri Hasko, Spence Hilton, and Kazuhiro Masaki, 2001, "The main features of the monetary policy frameworks of the Bank of Japan, the Federal Reserve and the Eurosystem," BIS Papers no. 9, Bank for International Settlements.

Borio, Claudio, 1997, "Monetary Policy Operating Procedures in Industrial Countries," in Implementation and Tactics of Monetary Policy, Bank for International Settlements, 3: 286-368.

Bindseil, Ulrich, 2000, "Towards a Theory of Central Bank Liquidity Management," Kredit and Kapital 3: 346-376.

Campbell, John, 1987, "Money Announcements, the Demand for Bank Reserves, and the Behavior of the Federal Funds Rate within the Statement Week," Journal of Money, Credit and Banking 19: 56-67.

Clinton, Kevin, 1997, "Implementation of Monetary Policy in a Regime with Zero Reserve Requirements," Bank of Canada working paper \#97-8.

Clouse, James and James Dow, 1999, "Fixed Costs and the Behavior of the Federal Funds Rate," Journal of Banking and Finance 23: 1015-1029. , 2001, "A Computational Model of Banks' Optimal Reserve Management Policy," Journal of Economic Dynamics \& Control 26: 1787-1814.

Davies, Haydn, 1998, "Averaging in a Framework of Zero Reserve Requirements," Bank of England working paper \#84.

Ewerhart, Christian, 2002, "A Model of the Eurosystem's Operational Framework for Monetary Policy Implementation," European Central Bank working paper \#197.

Furfine, Craig, 2000, "Interbank Payments and the Daily Federal Funds Rate," Journal of Monetary Economics 46: 535-553.

Goodfriend, Marvin, 2002, "Interest on Reserves and Monetary Policy," Economic Policy 
Reveiw, Federal Reserve Bank of New York, May: 77-84.

Guthrie, Graeme, and Julian Wright, 2000, "Open Mouth Operations," Journal of Monetary Economics 24: 489-516.

Hamilton, James, 1996, "The Daily Market for Federal Funds," Journal of Political Economy 104: 26-56.

Heller, Daniel, and Yvan Lengwiler, 2003, "Payment Obligations, Reserve Requirements, and the Demand for Central Bank Balances," Journal of Monetary Economics 50: 419-432.

Ho, Thomas and Anthony Saunders, 1985, "A Micro Model of the Federal Funds Market," Journal of Finance 40: 977-990.

Kopecky, Kenneth and Alan Tucker, 1993, "Interest Rate Smoothness and the Nonsettling-Day Behavior of Banks," Journal of Economics and Business 45: $297-314$.

Longworth, David, 1989, "Optimal Behavior of Direct Clearers in a World with Zero Reserve Requirements," working paper, Bank of Canada.

Orr, D. and W. G. Mellon, 1961, "Stochastic Reserve Losses and Expansion of Bank Credit," American Economic Review 51: 614-623.

Poole, William, 1968, "Commercial Bank Reserve Management in a Stochastic Model: Implications for Monetary Policy," Journal of Finance 23: 769-791.

Spindt, Paul and J. Hoffmeister, 1988, "The Micromechanics of the Federal Funds Market," Journal of Financial and Quantitative Analysis 23: 401-416.

Woodford, Michael, 2001, "Monetary Policy in the Information Economy," working paper, Princeton University. 